\title{
Rapid Neurodevelopmental Assessment (RNDA) : An Important Tool for Assessment of Psychomotor Development in Children with Perinatal Events
}

\author{
Dhananjoy Das ${ }^{1 *}$ \\ Kawsar Sultana ${ }^{2}$ \\ Golam Mohammed Tayeb $\mathrm{Ali}^{3}$ \\ Tanuka Barua ${ }^{4}$ \\ Mahmood A Chowdhury (Arzu) ${ }^{1}$
}

\footnotetext{
${ }^{1}$ Department of Pediatric Neurology Chattagram Maa-O-Shishu Hospital Medical College Chattogram, Bangladesh.

${ }^{2}$ Department of Community Medicine

Chattagram Maa-O-Shishu Hospital Medical College Chattogram, Bangladesh.

${ }^{3}$ Department of Pediatrics

Rangamati Medical College

Rangamati, Bangladesh.

${ }^{4}$ Department of Pediatrics

Chattagram Maa-O-Shishu Hospital Medical College
} Chattogram, Bangladesh.

\begin{abstract}
Background: Infants with various perinatal events are at risks for long term neurodevelopmental impairments. Neurodevelopmental assessment at early life has been considered as a valuable tool for prediction of neurodevelopmental outcomes in this population. This present study aimed to identify the neurodevelopmental impairments in high risk children by Rapid Neurodevelopment Assessment (RNDA)
\end{abstract}

Materials and methods : This was a cross sectional study conducted in the Autism and Child Development Centre of Chattogram Maa Shishu-O-General Hospital during the period of October to December 2018. Babies aged 0 -2 years with different perinatal events like prematurity, birth asphyxia, neonatal jaundice, and without any adverse event; that attended RNDA clinic underwent Rapid Neurodevelopmental Assessment (RNDA) to find at risk children for long term neurodevelopmental impairments.

Results: Among the 50 study subjects, Perinatal asphyxia was found in 41(82\%). 26(52\%) had history of IUGR, 22(44\%) had Preterm delivery and 25(50\%) had history of Neonatal convulsion. History of neonatal jaundice was found in 14(28\%) cases. $5(10 \%)$ children did not have any perinatal event. The Mean \pm SD age of study subjects was 7.38 \pm 7.31month. Severe impairment in gross motor and fine motor function were found in $25(50 \%)$ and $24(48 \%)$ respondents respectively. Vision was severely impaired in 10(20\%) cases. Severe cognition and behavior impairment were found in $8(16 \%)$ and $3(6 \%)$ cases accordingly. Severe hearing and speech impairment were found in $2(4 \%) \& 10(20 \%)$ cases respectively. Severe seizure was found in 19(39\%) cases. Study subjects with the history of delayed cry or Perinatal asphyxia had significantly decreased fine motor skills. Children born with IUGR had significant gross motor and fine motor skill impairment. Significant speech \& cognitive impairment were observed in children with neonatal jaundice. Seizure was found significant in study subjects with a history of neonatal convulsion.

Conclusion: Rapid Neurodevelopment Assessment (RNDA) plays an important role for early identification of neurodevelopmental impairments of high-risk infants and thus screening for these can promote early therapeutic intervention and subsequent follow up, leading to better outcome.

Key words: Rapid Neurodevelopmental assessment (RNDA); Perinatal events; Psychomotor development.

\section{INTRODUCTION}

Despite the fact that infant mortality in Bangladesh is diminishing because of improved NICU care and different healthprograms, morbidity is increasing simultaneously at an alarming rate. Premature babies or asphyxiated babies who survive may have long term poor psychomotor outcome, making them a burden to their families and society. Around $5-15 \%$ of premature infants who survive have cognitive, behavioral and social challenges ${ }^{1}$. The estimated prevalence of Cerebral Palsy (CP) is 
3.7/1000 children in Bangladesh ${ }^{2}$. Risk factors include birth asphyxia and prematurity where the latter increases the risk 33 times more than that for normal babies ${ }^{3}$. An epidemiologic survey of disabilities among 2 to 9-year-old children in Bangladesh, revealed 68 out of 1000 had some form of disability related to motor, vision, hearing, cognitive, disabilities and seizer disorder ${ }^{4}$.

Rapid Neurodevelopmental Assessment (RNDA) is a reliable and valid neurodevelopmental assessment tool based upon the International Classification of Function (ICF, WHO, 2010) that is currently being used in children aged 0-15 years. RNDA is particularly useful for early identification of children at high risk for neurodevelopmental impairments ${ }^{5}$

Developmental therapy is the combination of various developmental stimulation like physical stimulation, cognitive stimulation and visual stimulation etc ${ }^{6-8}$. Early intervention programmes in this form is more suitable to promote growth and development of risky babies who are comparatively more susceptible to growth and developmental delay.

At present, our primary health care services do not include screening for the developmentally delayed child ${ }^{9}$. A more recent survey suggests that, although the prevalence of disabilities may not have changed in the past decade, a shift from serious and obvious disabilities to milder problems related to cognitive disability, behavioral problems, hearing impairments and speech and language delay has been noticed ${ }^{10}$.

The purpose of this study was to identify neurodevelopmental impairments in high-risk babies with a variety of perinatal events, using Rapid Neurodevelopmental Assessment (RNDA) and hence provide early therapeutic intervention and subsequent follow up as an attempt to limit further deterioration of their condition. Thus, this study is of a valuable aid in preventing and ameliorating developmental impairment in these highrisk babies.

\section{MATERIALS AND METHODS}

The study was a cross-sectional one carried out in the Autism and Child Development Centre of Chattogram Maa-Shishu O General Hospital, during the period of 0ctober to December 2018. Babies aged $0-2$ years with different perinatal events like prematurity, birth asphyxia, neonatal jaundice, and without any event attending the RNDA clinic of Child Development Centre for neurodevelopmental assessment were enrolled as study subjects. All subjects were assessed by RNDA tool. It is a reliable and valid neurodevelopmental assessment tool based upon the International Classification of Function (ICF, WHO, 2010). The following developmental domains were assessed: primitive reflexes (Only for children $<1$ month) gross motor, fine motor, vision, hearing, speech, cognition, behavior and seizures. Different items appropriate for age were used for assessment of particular domains. Mild, moderate and severe grading was applied according to the abilities of the subject to perform various tasks. Score "0" is assigned to mild grade, score" 1" and score " 2 " is assigned to moderate and severe grade respectively. A final summary sheet at the end of the assessment is used to describe the severity of impairment in each domain by adding the scores in accordance with number of items that are used 5 . Categorization was done according to the severity of neurodevelopmental impairment.

\section{RESULTS}

A total 50 children aged 0-2 years, who attended the Autism and Development Centre of Chattogram Maa- Shishu O General Hospital, during the period of 0ctober to December 2018 were enrolled as study subject. Among the study subjects most of the children had a history of Perinatal asphyxia 41(82\%). $26(52 \%)$ had history of IUGR, 22(44\%) had preterm delivery and $25(50 \%)$ had history of neonatal convulsion. History of neonatal jaundice was found in $14(28 \%)$ cases. $5(10 \%)$ children did not have any perinatal events. The Mean \pm SD age of study subjects was $7.38 \pm 7.31$ month. Impairment in gross motor and fine motor function was the prominent findings in the study subject which were found to be severely affected in $25(50 \%)$ and $24(48 \%)$ respondents respectively, mild to moderately affected in $13(26 \%) \& 10(20 \%)$ and $12(24 \%) \& 10(20 \%)$ cases subsequently. 2(4\%) and 4(8\%) had normal gross motor and fine motor function. Severe vision and speech impairment were found in $10(20 \%)$ cases, mild to moderate impairment found in $16(32 \%) \& 4(8 \%)$ and $13(26 \%) \& 2(4 \%)$ study subject. Normal vision and speech was found in 20(40\%) and 18(36\%) study subject. Severe cognition and behavior impairment were found in $8(16 \%)$ and $3(6 \%)$ cases, mild to moderate impairment found in $18(36 \%) \& 2(4 \%)$ and $11(22 \%) \& 1(2 \%)$ study subject. Normal cognition and behavior development found in $22(44 \%)$ and $35(70 \%)$ cases. Severe hearing impairment was found in $2(4 \%)$ cases, mild to moderate impairment found in $13(26 \%)$ and 2(4\%) cases. Normal hearing was found in 33(66\%) study subject. Severe seizure was found in $19(39 \%)$ cases mild to moderate seizure was found in $3(6 \%)$ and $4(8 \%)$ study subject. $22(44 \%)$ of study subject did not have seizure.

Table I : Distribution of study subjects according to perinatal events.

\begin{tabular}{lrr} 
Perintal events & Number of children & Percentage \\
Prematurity & 22 & $44 \%$ \\
IUGR & 26 & $52 \%$ \\
Delayed Cry or PNA & 41 & $82 \%$ \\
Neonatal jaundice & 14 & $28 \%$ \\
Neonatal Convulsion & 25 & $50 \%$ \\
Normal & 5 & $10 \%$ \\
Unknown & 2 & $4 \%$ \\
\hline
\end{tabular}




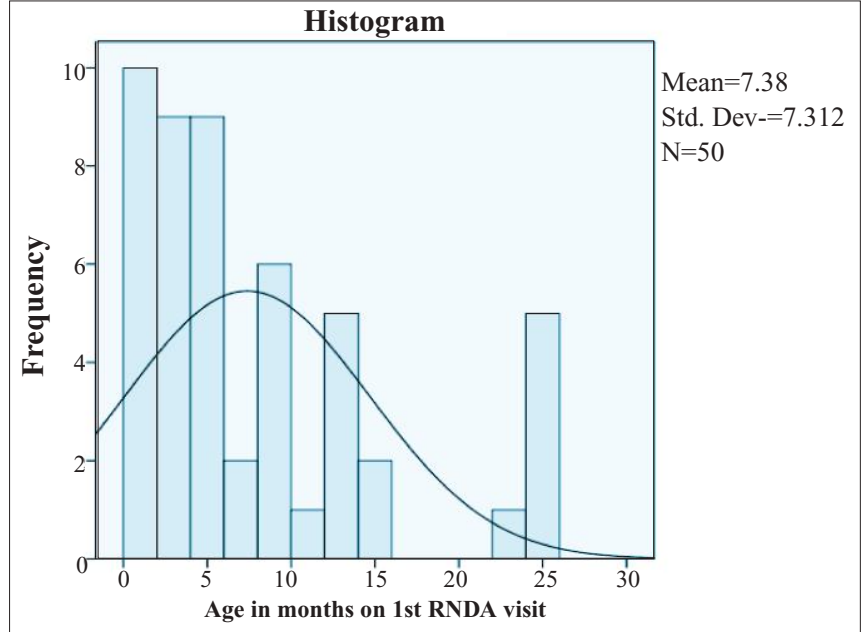

Figure 1 : Distribution of study subject according to age.

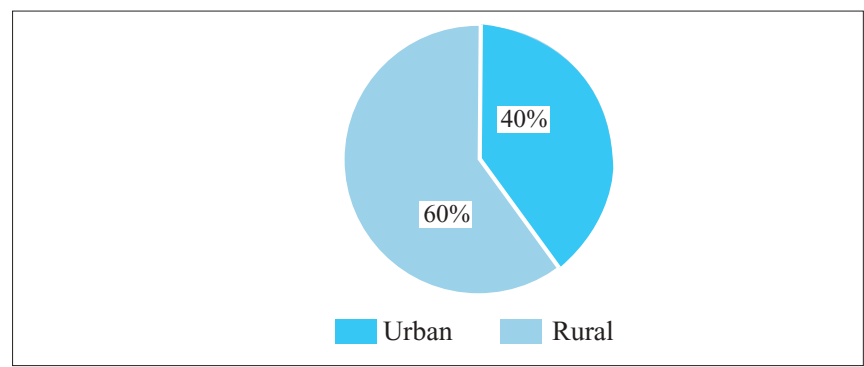

Figure 2 : Residence of the study subjects.

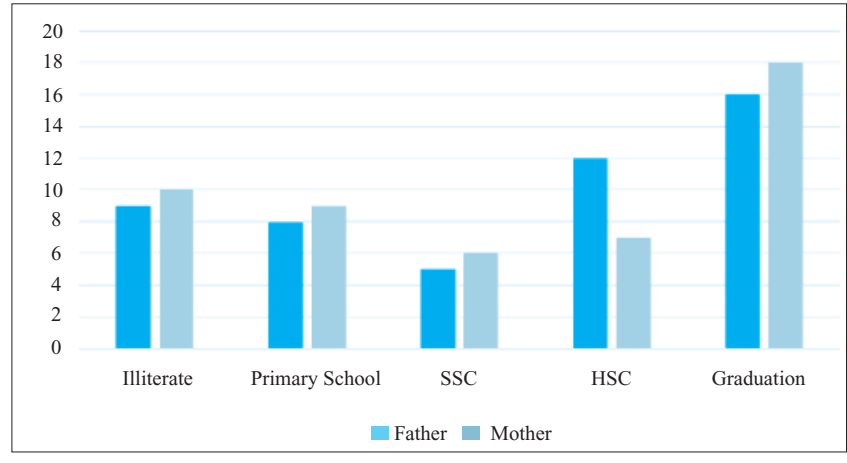

Figure 3 : Educational status of the parents.

Table II : Categorization of developmental domains according to the severity.

\begin{tabular}{lrrrrr} 
RNDA & Normal & Mild & Moderate & Severe & Total \\
Primitive reflexes & 0 & $2(60 \%)$ & 0 & 1 & 3 \\
Gross Motor & $2(4 \%)$ & $13(26 \%)$ & $10(20 \%)$ & $25(50 \%)$ & 50 \\
Fine Motor & $4(8 \%)$ & $12(24 \%)$ & $10(20 \%)$ & $24(48 \%)$ & 50 \\
Vision & $20(40 \%)$ & $16(32 \%)$ & $4(8 \%)$ & $10(20 \%)$ & 50 \\
Hearing & $33(66 \%)$ & $13(26 \%)$ & $2(4 \%)$ & $2(4 \%)$ & 50 \\
Speech & $18(36 \%)$ & $6(12 \%)$ & $6(12 \%)$ & $10(20 \%)$ & 50 \\
Cognition & $22(44 \%)$ & $18(36 \%)$ & $2(4 \%)$ & $8(16 \%)$ & 50 \\
Behavior & $35(70 \%)$ & $11(22 \%)$ & $1(2 \%)$ & $3(6 \%)$ & 50 \\
Seizures & $22(45 \%)$ & $3(6 \%)$ & $4(8 \%)$ & $19(39 \%)$ & 48 \\
\hline
\end{tabular}

Table III : Number of children with different perinatal events in each RNDA category based on severity.

\begin{tabular}{|c|c|c|c|c|c|c|c|c|c|c|c|}
\hline \multirow[t]{2}{*}{ RNDA } & \multirow[t]{2}{*}{$\begin{array}{l}\text { Degree of } \\
\text { severity }\end{array}$} & \multirow[t]{2}{*}{ Prematurity } & \multicolumn{3}{|c|}{ IUGR } & \multirow[t]{2}{*}{$\begin{array}{r}\text { Neonatal } \\
\text { convulsion }\end{array}$} & \multicolumn{3}{|c|}{$\begin{array}{l}\text { Neonatal } \\
\text { Jaundice }\end{array}$} & \multirow[t]{2}{*}{ PNA } & \multirow[b]{2}{*}{ Total } \\
\hline & & & Total & & Total & & Total & & Total & & \\
\hline \multirow[t]{3}{*}{ Premitive reflexes } & Mild & $2(1 \%)$ & & $2(1 \%)$ & & $1(0.5 \%)$ & & - & & $1(0.5 \%)$ & \\
\hline & Moderate & - & $2(1 \%)$ & - & $3(1.5 \%)$ & - & $2(1 \%)$ & - & & - & $2(1 \%)$ \\
\hline & Severe & - & & $1(0.5 \%)$ & & $1(0.5 \%)$ & & - & & $1(0.5 \%)$ & \\
\hline \multirow[t]{3}{*}{ Gross motor } & Mild & $5(2.5)$ & & $9(4.5 \%)$ & & $2(1 \%)$ & & $2(1 \%)$ & & $6(3 \%)$ & \\
\hline & Moderate & $6(3 \%)$ & $17(8.5)$ & $6(3 \%)$ & $24(12 \%)$ & $6(3 \%)$ & $23(11.5 \%)$ & $2(1 \%)$ & $12(6 \%)$ & $10(5 \%)$ & $39(19.5 \%)$ \\
\hline & Severe & $6(3 \%)$ & & $9(4.5 \%)$ & & $15(7.5 \%)$ & & $8(4 \%)$ & & $23(11.5 \%)$ & \\
\hline \multirow[t]{3}{*}{ Fine motor } & Mild & $6(3 \%)$ & & $8(4 \%)$ & & $2(1 \%)$ & & $2(1 \%)$ & & $7(3.5 \%)$ & \\
\hline & Moderate & $6(3 \%)$ & $24(12 \%)$ & $6(3 \%)$ & $22(11 \%)$ & $7(3.5 \%)$ & $23(11.5 \%)$ & $2(1 \%)$ & $12(6 \%)$ & $10(5 \%)$ & $39(19.5 \%)$ \\
\hline & Severe & $8(4 \%)$ & & $8(4 \%)$ & & $14(7 \%)$ & & $8(4 \%)$ & & $22(11 \%)$ & \\
\hline \multirow[t]{3}{*}{ Vision } & Mild & $7(3.5 \%)$ & & $11(5.5 \%)$ & & $4(2 \%)$ & & $4(2 \%)$ & & $9(4.5 \%)$ & \\
\hline & Moderate & $4(2 \%)$ & $15(7.5)$ & $4(2 \%)$ & $18(9 \%)$ & $2(1 \%)$ & $13(6.5 \%)$ & $2(1 \%)$ & $18(4 \%)$ & $4(2 \%)$ & $23(11.5 \%)$ \\
\hline & Severe & $4(2 \%)$ & & $3(1.5 \%)$ & & $7(3.5 \%)$ & & $2(1 \%)$ & & $10(5 \%)$ & \\
\hline \multirow[t]{3}{*}{ Hearing } & Mild & $7(3.5 \%)$ & & $10(5 \%)$ & & $7(3.5 \%)$ & & $3(1.5 \%)$ & & $3(1.5 \%)$ & \\
\hline & Moderate & $1(0.5 \%)$ & $9(4.5 \%)$ & $1(0.5 \%)$ & $12(6 \%)$ & $1(0.5 \%)$ & $9(4.5 \%)$ & & $5(2.5 \%)$ & & $1.50 \%$ \\
\hline & Severe & $1(0.5 \%)$ & & $1(0.5 \%)$ & & $1(0.5 \%)$ & & $2(1 \%)$ & & & \\
\hline \multirow[t]{3}{*}{ Speech } & Mild & $8(4 \%)$ & & $9(4.5 \%)$ & & $9(4.5 \%)$ & & $5(2.5 \%)$ & & $13(6.5 \%)$ & \\
\hline & Moderate & $4(2 \%)$ & $16(7 \%)$ & $4(2 \%)$ & $17(8.5 \%)$ & $2(1 \%)$ & $18(9 \%)$ & $1(0.5 \%)$ & $12(6 \%)$ & $5(2.5 \%)$ & $27(13.5 \%)$ \\
\hline & Severe & $4(2 \%)$ & & $4(2 \%)$ & & $7(3.5 \%)$ & & $6(3 \%)$ & & $9(4.5 \%)$ & \\
\hline \multirow[t]{3}{*}{ Cognition } & Mild & $9(4.5 \%)$ & & $11(5.5 \%)$ & & $9(4.5 \%)$ & & $4(2 \%)$ & & $14(7 \%)$ & \\
\hline & Moderate & & $14(7.5)$ & & $15(7.5 \%)$ & $1(0.5 \%)$ & $15(7.5 \%)$ & & $10(5 \%)$ & $1(0.5 \%)$ & $22(11 \%)$ \\
\hline & Severe & $5(2.5 \%)$ & & $4(2 \%)$ & & $5(2.5 \%)$ & & $6(3 \%)$ & & $7(3.5 \%)$ & \\
\hline \multirow[t]{3}{*}{ Behaviour } & Mild & $3(1.5 \%)$ & & $3(1.5 \%)$ & & $5(2.5 \%)$ & & $3(1.5 \%)$ & & $8(4 \%)$ & \\
\hline & Moderate & & $6(3 \%)$ & & $6(3 \%)$ & $1(0.5 \%)$ & $8(4 \%)$ & & $6(3 \%)$ & $1(0.5 \%)$ & $12(6 \%)$ \\
\hline & Severe & $3(1.5 \%)$ & & $3(1.5 \%)$ & & $2(1 \%)$ & & $3(1.5 \%)$ & & $3(0.5 \%)$ & \\
\hline \multirow[t]{3}{*}{ Seizures } & Mild & $1(0.5 \%)$ & & $1(0.5 \%)$ & & $1(0.5 \%)$ & & & & $2(1 \%)$ & \\
\hline & Moderate & $3(1.5 \%)$ & $12(6 \%)$ & $3(1.5 \%)$ & $14(7 \%)$ & $2(1 \%)$ & $16(8 \%)$ & & & $4(2 \%)$ & $24(12 \%)$ \\
\hline & Severe & $8(4 \%)$ & & $10(5 \%)$ & & $13(6.5 \%)$ & & $6(3 \%)$ & & $18(9 \%)$ & \\
\hline
\end{tabular}


Table IV : Comparison of different perinatal events in terms of all RNDA parameters according to Mann-Whitney U test.

\begin{tabular}{lccccr} 
RNDA parameters & Prematurity & IUGR & Convulsion & Jaundice & PNA \\
Primitive reflexes & 0.157 & & 0.48 & & 0.48 \\
Gross motor & 0.282 & 0.009 & 0.107 & 0.833 & 0.058 \\
Fine motor & 0.222 & 0.003 & 0.104 & 0.643 & 0.04 \\
Vision & 0.215 & 0.589 & 0.967 & 0.784 & 0.688 \\
Hearing & 0.343 & 0.115 & 0.789 & 0.697 & 0.822 \\
Speech & 0.297 & 0.892 & 0.215 & 0.017 & 0.375 \\
Cognition & 0.223 & 0.914 & 0.465 & 0.029 & 0.987 \\
Behavior & 0.79 & 0.535 & 0.655 & 0.126 & 0.855 \\
Seizures & 0.621 & 0.702 & 0.02 & 0.815 & 0.078 \\
\hline
\end{tabular}

\section{DISCUSSION}

Children born with different perinatal events are at risk for major and minor neurodevelopmental disabilities. Prediction of neurodevelopmental outcome of these 'high-risk' group of children is very important for early therapeutic interventions. Information regarding the severity and spectrum of impairments is essential for counseling parents, tailoring follow up services and introducing early intervention programs. A detailed neurological examination in early infancy is a valuable tool for predicting outcome ${ }^{11}$. This study was done to find the neurodevelopmental impairments in high risk babies by RNDA which may aid in identifying at risk infants of long-term neurodevelopmental impairment.

In this study mean age of study subjects on their first visit to RNDA clinic was 7.38 months. However, it is commendable for patients to come for a RNDA with in the first month after birth. Pediatricians and primary health care givers should counsel new mothers to have their child assessed for neurodevelopmental disabilities as early as possible so that appropriate developmental stimulation therapy can be initiated to minimize lifelong disabilities.

A study carried out on 159 Bangladeshi preterm infants by Khan et al showed that maternal education influenced the developmental outcome of children ${ }^{12}$. In our study, it was observed that most parents completed graduation suggesting there was at least some educational influence though a significant advantage could not be deciphered.

Among the 50 study subjects who underwent RNDA, impairment in gross motor and fine motor function were found to be severely affected in $25(50 \%)$ and $24(48 \%)$ respondents respectively. Some studies showed that motor performance of children with different perinatal events is affected in $20 \%-40 \%$ which is consistent with this study. If diagnosed early the severity of motor functions can be minimized through proper developmental therapy. However, if it is delayed it can affect the daily living activities and quality of life of the child. A randomized control trial on 27 children conducted by Lekskulchai and Cole et al revealed that development intervention programme has a beneficial effect on children with perinatal events ${ }^{13}$.
Among the study subjects severe vision impairment was observed in $10(20 \%)$ cases. Only $2(4 \%)$ cases had severe hearing impairment. Speech impairment was found in 10(20\%) respondents. Severe cognition and behavior impairment were identified in $8(16 \%) \& 3(6 \%)$ cases respectively. Severe seizure was found in $19(39 \%)$ study subject. This study revealed that a high proportion of children had identifiable problems in more than one domain which, in turn, indicates that RNDA plays an important role for identification of developmental delay in different domains and a follow up RNDA becomes mandatory. In this study, most of the study subjects had more than one perinatal event and the distribution of cases were made based on the presence or absence of a particular event. Thus, cases having multiple perinatal events were added in more than one category based on the occurrence of those events.

In this study, 41(82\%) children were found with a history of delayed cry or Perinatal Asphyxia (PNA) at birth. 39(19.5\%) of study subjects with PNA were found to have gross motor and fine motor abnormality. Fine motor skill was significantly worse in children with PNA as compared to other perinatal events $(\mathrm{p}=0.04)$. Vision and speech impairment were found in $23(11.5 \%)$ and $27(13.5 \%)$ respectively. Cognitive and behavioral function affected in $22(11 \%)$ and $12(5 \%)$ study subjects with PNA. Seizure was found in 24(12\%). Developmental outcome in infants with PNA depends on Sarnat's clinical staging system. Categorization of PNA in to HIE-1, HIE-II and HIE-III could not be done in this study as it is a cross sectional study. But it is assumed that all cases are belonging to HIE-II and HIE-III, as infants with PNAHIE-Iusually donot come for follow up. Charlene et al stated that $62 \%$ of those with severe encephalopathy had poor developmental outcome compared to $25 \%$ with moderate $\mathrm{HIE}^{14}$. Behera et al showed in their study $100 \%$ of HIE- III had neurological abnormality and $36.4 \%$ of HIE -II developed neurological abnormality ${ }^{15}$. Behera et al also showed in their study $27 \%$ of HIE-III and $9 \%$ of HIE-II had vision problems in the form of squint \& cortical blindness while another study by Marlow et al showed that $13-25 \%$ of HIE -III had blindness ${ }^{16}$. Both Shankaran et al and Marlow et al found $6.18 \%$ of HIE-III had hearing impairment ${ }^{17,16}$.

In this study, 26(52\%) of study subjects had a history of IUGR at birth. Gross motor and fine motor impairment were found in $24(12 \%)$ and $22(11 \%)$ cases. Hearing and speech impairments were observed in $12(6 \%)$ and $17(8.5 \%)$ respectively whereas visual impairment was found in 18(9\%). 15(7.5\%) and 6(3\%) study subjects with IUGR had cognitive and behavioral impairment and $14(7 \%)$ of them had seizures. Primitive reflex abnormality was found in $3(1.5 \%)$. Gross motor and fine motor skills were found to be diminished significantly in cases with IUGR in this study ( $p=0.009 \& p=0.003$ ). Babies born with IUGR regardless of preterm or term infants are at risk of adverse neurodevelopmental outcome during childhood. Al-Qashar et al showed in their study that almost $50 \%$ of the IUGR infants had lower scores (Moderate $35.4 \%$ and severe $13.4 \%$ according to Baley Infant Neurodevelopmental Screening) irrespective of 
the gestational age or birth weight ${ }^{18}$. IUGR babies may be associated with worse neurocognitive impairments including $\mathrm{CP}$, poor academic performance, poor memory, abnormal emotional and behavioral problem and social disorder. Jarvis et al found that IUGR term infants had 4 to 6 times the rate of $\mathrm{CP}^{19}$.

$22(44 \%)$ of study subject in this study were found to be born preterm. Among this $17(8.5 \%)$ and $24(12 \%)$ cases had gross motor and fine motor function impairment. Hearing and speech impairment was revealed in $9(4.5 \%)$ and $16(8 \%)$ while vision impairment was observed in 15(7.5\%). Cognitive and behavioral impairment was found in $19(7 \%)$ and $6(3 \%)$ and seizures were observed in $12(6 \%)$. Primitive reflex abnormality was found in only $2(1 \%)$. There is no significant difference observed in terms of RNDA parameter in comparison with other perinatal events. These study findings consistency with Islam et al who conducted a study among 103 preterm neonates at 3 month of age and showed that motor performance of children born prematurely is affected in $20-40 \%{ }^{20}$. Poorer neurodevelopmental outcome in premature babies is multifactorial and it is likely a consequence of an immature brain, perinatal risk factors and environmental exposure. Greater gestational age at birth and higher birth weight is associated with a lower risk of developmental delay. Do et al in their study showed, incidence of $\mathrm{CP}$ among premature baby were $7 \%$. Moreover, they found premature babies had higher impairment in cognition, language and motor skills by $17 \%, 8 \%$ and $4 \%$ respectively according to Baley Scales of infant and toddler development and the AmielTison's neurological examination method ${ }^{21}$.

In this study $25(50 \%)$ study subjects were found to have a history of neonatal convulsion. Gross motor and fine motor impairment were observed in $23(11.5 \%)$ cases. Hearing and speech impairment were found in $9(4.5 \%)$ and $18(9 \%)$. Vision impairment was found in 13(6.5\%); seizure observed in 16(8\%) and primitive reflex abnormality was found in only $2(1 \%)$. Significant form of seizure was observed in respondents with the history of neonatal convulsion in comparison with other perinatal events $(p=0.02)$. A study conducted by Kharoshankaya et al revealed that in moderate to severe HIE presence of seizure alone was not associated with abnormal outcome at 24-48 months ${ }^{22}$. Total seizure burden of more than 40 minutes and maximum seizure burden of more than 13 minutes were associated with significantly higher risk of abnormal development. Etiology associated with poor outcome included cerebral dysgenesis, global cerebral hypoxic insult and CNS infection. Conversely, infants with focal cerebral hypoxic insult, transient metabolic disturbance or idiopathic seizure associated with favorable outcome was observed in the study by Tekgul et $\mathrm{al}^{23}$.
$14(28 \%)$ study subject in this study were found to have history of neonatal jaundice. Among this, 12(6\%) had gross motor and fine motor impairment. Hearing and speech impairment were observed in 5(2.5\%) and $12(6 \%)$ vision impairment was found in $8(4 \%) .10(5 \%)$ and $6(3 \%)$ of subjects had cognitive and behavioral impairment. In this study, speech and cognition was impaired significantly in children with neonatal jaundice in comparison with other perinatal events $(p=0.017 \& p=0.029)$. It is also an important cause of neurodevelopmental sequelae in Bangladesh. This study finding was consistent with Gordon et al who found that $22(96 \%)$ of children with Neonatal Jaundice at age 18-32 month had motor or neurological impairement, $43 \%$ were unable to either sit and or stand independently, $48 \%$ had movement disorder and $56 \%$ had eye movement dis$\operatorname{order}^{24}$.

So neurodevelopmental assessment during early infancy can predict long term impairment which may help in screening at risk infants. This study strongly support scarrying out neurodevelopmental assessment by RNDA on high risk babies.

\section{CONCLUSION}

Routine neurodevelopmental assessment by RNDA during neonatal period and frequent follow up at early months of infancy may strongly aid in identifying at risk infants for a long-term neurodevelopmental disability in the future. Knowledge of the severity and spectrum of impairments is necessary for counseling parents, tailoring follow up services and allocating early interventional programme.

\section{RECOMMENDATION}

Neurodevelopmental assessment should be initiated in all highrisk babies as early as possible. Neonatologist \& Pediatrician should be well concerned about the consequences of Neurological sequelae. Further study should be carried out with long term follow up RNDA to observe different developmental aspects and to see the effect of developmental therapy.

\section{LIMITATION}

Small sample size. Developmental outcome could not be assessed after providing developmental therapy.

\section{DISCLOSURE}

All the authors declared no competing interest. 


\section{REFERENCES}

1. Cook RW. Preterm morbidity and mortality over 25 years. Arch Dis Child fetal Neonatal Ed. 2008; 91:293-294.

2. Mohammed EI-Dib, Massuro AN, Dorothy B. Neuroimaging and Neurodevelopmental Outcome of Premature infants. Am J perinatol. 2009; 27:807-818.

3. Hai MSBA, Sarker RN, Akter A, Biswas P, Kunda GC, Mehedi MT. Determinant of Cerebral Palsy among under 5 Children. Bangladesh Med J. 2015;40(1):13 -17.

4. Khan N, Durkin M. Framework: Prevalence In: Zinkin P, McConachic H, eds. Disabled Children and Developing Countries: Clinics in Developmental Medicine No 136, London, United Kingdom: Mackeith Press. 1995;1-9.

5. Islam MZ, Hossain MM, Haque SH, Khan NZ. Neurodevelopmental Assessment in Preterm Neonates at Early Ages: Screening of at risk infants for long Term Sequelae. Bangladesh J Child Health. 2016;40(1):5-11.

6. The state of the worlds children, UNICEF. New York and Oxford University press. Oxford UK. 2001.

7. Khan MR, Rahman ME. Essence of pediatrics.3rd ed Dhaka. Anwara Khan. 2004;3-17.

8. Sturney P, Thorbern MJ, Brown JM, Reed J, KingG. Protage guide to early intervention: crossecultural aspects and intercultural variability. J ofChild Care Health and Dev. 1992;18:377-394.

9. State of the World's Children: Childhood Under Threat United Nations Childrens Fund New York,NY. 2005.

10. Femous S, Khan NZ, Durkin MS. Prevalence of Childhood Disability: the total TOF study in Bangladesh. Presented at International Association for the Scientific: Study of Intellectual Disabilities ( IASSID) Conference. Montpellier France. 2004.

11. Beatric L. Prediction of Neurodevelopmental outcome after preterm birth, doi: 10, 1016/ J.pediatrnerol, Elsevier, Inc. 2009.

12. Khan NZ, Muslima H, Parveen M, BhottacharyaM, Begum N, Chowdhury S. Neurodevelopmental out come of preterm infants in Bangladesh.Pediatrics. 2006;3:3-17.

13. Lekskulchai R, Cole J, Effects of developmental programme on motor performance in infants born preterm. Aus J of physiother. 2001;47:169176.

14. Charlene MT Robertson, Max Perlman. Follow-up of the term infant after hypoxic-ischemic encephalopathyPaediatr Child Health. 2006;11(5):278-282.

15. Behera A, Murmu M.C, Sahoo R. Study of neurodevelopmental outcome of hypoxic ischemic encephalopathy of less than one-year infant in a tertiary care institute. Int J Pediatr Res. 2018;5(2):93-99.

16. Marlow N, Rose AS, Rands CE, Draper ES. Neuropsychological and educational problems at school age associated with neonatal encephalopathy Arch DisChild Fetal Neonatal Ed. 2005; 90 (5): F380-387.

17. Seetha Shankaran, Abbot R. Laptook, Jon E. Tyson,Scott A. Mc Donald, Edward F. Donovan et al. WholeBody Hypothermia for Neonates with Hypoxic-Ischemic Encephalopathy N Engl J Med. 2005; 353:1574-1584.

18. Al-Qashar F, Sobaih B, Shajira E, Al Saif S, Ahmed IA, Al-Shehri H, et al. Impact of intrauterine growth restriction and birth weight on infant's early childhood neurodevelopment outcome. J Clin Neonatol. 2018;7:1-6.

19. Jarvis S, Glinianaia SV, Torrioli MG, Platt MJ, Miceli M, Jouk PS, et al. Cerebral palsy and intrauterine growth in single births: European collaborative study. Lancet. 2003;362:1106-1111.

20. Islam MZ, Hossain MM, Haque SA, Khan NZ. Neurodevelopmental Assessment in Preterm Neonates at Early Ages: Screening of at-risk Infants for Long Term Sequlae.BANGLADESH J CHILD HEALTH 2016; 40 (1) : 5-11.

21. Do CHT, Kruse AY, Wills B et al. Neurodevelopment at 2 years corrected age among Vietnamese preterm infants. Arch Dis Child. 2020; 105:134-140

22. Kharoshankaya L, Stevenson N, livingstone V, Marry DM, Murphy BP, Aheane CE, Boylan GB. Seizure Burden and Neurodevelopmental Outcome in Neonates with Hypoxic- Ischemic Encephalophathy. Developmental Medicine \& Child Neurology. 2016;58:1242-1248.

23. Tekgul H, Gauvream K, Soul J, Murphy L, Robertson R, Stewart J et al. The Current Profile and Neurodevelopmental Outcome of Seizure In Term Neuborn Infant. Pediatrics. 2006; 117: 1270-1280.

24. Gordon AL, English M, Dzombo T, Karisa M. Neurological and Developmental Outcome of Neonatal jaundice and Sepsis in Rural kenya. Tropical Medicine and International Health. 2005; 10(11): 1114-1120. 